\title{
EVALUATING THE PERFORMANCE OF AMPUTEE SERVICES AT NEIGHBOURING HOSPITALS: A RISK ADJUSTED PERFORMANCE ANALYSIS
}

\author{
B. Hordacre', M. Crotty ${ }^{1}$, C. Pham ${ }^{2}$, J. Karnon ${ }^{2}$
}

\begin{abstract}
Background: Despite advances in vascular surgery techniques, ageing populations and increasing rates of vascular disease and diabetes have contributed to relatively steady amputation rates. Older amputees have limited life expectancies and often require expensive rehabilitation interventions on top of vascular procedures. Services warrant scrutiny with view to reducing clinical practice variations, improving hospital performance and securing the best patient outcomes. Objective: This study employed a novel methodology to assess 12-month hospital performance associated with provision of lower-limb amputee services at three neighbouring hospitals. Design and Setting: Routinely collected data on individuals having an initial lower-limb amputation from July 2001 to June 2008 at three hospital networks in Adelaide, South Australia were analysed. Observed and expected lengths of stay and patient outcomes were generated, from which relative performance across hospitals were compared. Results: Following amputation we observed a short time-to-death (0.8 years, IQR 0.21-2.12) and 12-month mortality rate of 25\% (unadjusted). Riskadjusted analyses indicated that one hospital with co-located vascular and rehabilitation services had greater performance with lower re-amputation rates and fewer deaths. However, length of stay at this hospital was longer than expected. Conclusion: The risk-adjusted performance analysis provided an approach which could inform further investigations around variation in hospital performance to inform best practice service delivery.
\end{abstract}

Key words: Amputation, vascular disease, rehabilitation, risk adjustment, process assessment (health care).

\section{Introduction}

Despite advances in vascular surgical techniques, the global diabetes epidemic $(1,2)$ has been associated with relatively steady numbers of major lower-limb amputations (3) and amputees in rehabilitation in developed nations $(4,5)$. Amputee presentations are often complex with high numbers of comorbidities (5-7). Recent reviews suggest that peripheral vascular disease (PVD), both with and without associated diabetes, will continue to increase globally, becoming a major public health burden $(8,9)$, with severe PVD presentations often leading to major limb amputation (10). These episodes represent complex cases for vascular health services, with associated demand for amputee rehabilitation. Given these complexities, variations in outcomes of both surgical and rehabilitation services are known to occur (4, $5,10-17)$. Little information is available on comparative

1. Department of Rehabilitation, Aged and Extended Care, Flinders University, South Australia, Australia; 2. School of Public Health, The University of Adelaide, South Australia, Australia.

Corresponding Author: Brenton Hordacre, Department of Rehabilitation and Aged Care, Repatriation General Hospital, Daws Road, Daw Park, Australia, 5041. Email: brenton.hordacre@adelaide.edu.au analyses of relative performance and outcomes of alternative forms of service delivery. With a growing volume of routinely collected episode data, opportunity exists to learn and improve hospital service provision and efficiency outcomes. The risk adjusted performance analysis methodology presented here represents an approach which can be used for observational comparative effectiveness research, and may provide important information about efficiency and effectiveness of health care provision across amputee services.

The aim of this study was to employ a novel methodology to assess resource use and outcomes associated with lower-limb amputation rehabilitation service in Adelaide, South Australia. Findings from this study provide insight into the relative efficiency of alternative South Australian amputee rehabilitation models, specifically rehabilitation services which are co-located with acute vascular services, and rehabilitation services provided in off-site facilities. 


\section{Methods}

\section{Data source}

Routinely collected data was obtained and linked from three separate sources in order to perform the analyses. Hospital separation data were extracted from the Integrated South Australian Activities Collection (ISAAC) dataset for all public and private hospitals in South Australia, from July 2001 to June 2008. Data were extracted from discharge summaries and describe patient characteristics, comorbidities, admission type, length of stay (LOS), primary and additional diagnoses and procedures. Comorbidity variables were coded based on the current clinical performance indicators for the Variable Life Adjusted Display (VLAD) system using International Classification of Diseases (ICD$10 \mathrm{AM}$ ) codes (18). All-cause mortality data from the Register of Births, Deaths and Marriages were linked to hospital separation data from July 2001 to June 2008 ( $\mathrm{N}=4,072,341$ hospital separations) based on a set of common identifiers, with mathematical algorithms to determine likelihood that a pair of records refers to the same individual (19). Socioeconomic data describing socioeconomic areas, socioeconomic disadvantage, economic resources, and education and occupation were obtained based on area (postcode) levels. Socioeconomic data were linked to ISAAC data by analysis of hospitalspecific identification numbers and postcodes. Ethical approval to conduct the study was provided by the South Australian Department of Health Human Research Ethics Committee.

\section{Study cohort}

Major lower-limb amputation separations were identified using ICD-10AM procedure codes (4436700, 4436701, 4436702, 4437000, 4437300). Minor lower-limb amputations including toe and partial foot amputations were not included in this analysis (ICD-10AM procedure codes 4433800, 4435800, 4436100, 4436101, 4436400, $4436401,9055700)$. The initial lower-limb amputation event was defined as the first lower-limb amputation hospital admission that occurred for a patient from July 1 , 2002 onwards to exclude patients who had experienced a recent lower-limb amputation (i.e. within the previous 12 months). Transfers for the same lower-limb amputation were excluded from the analysis so as to avoid double counting episodes, however associated LOS were included as part of the index episode of care.

Following identification of the initial lower-limb amputation, hospital admissions over the subsequent 12 months were assessed for each patient. These outcomes were selected in order to compare performance between hospital services. Patients were categorised into one of four mutually exclusive endpoints based on their first experienced event: (1) another lower-limb amputation of either the same limb (to a higher level) or the other limb (ICD-10AM procedure codes 4436700, 4436701, 4436702, 4437000, 4437300) (20-22), (2) stump revision or debridement (ICD-10AM procedure code 4437600, $3002300,3002301)(20-22)$, (3) no subsequent event or death, or (4) died without subsequent event. Although there are many outcomes experienced following an initial amputation, these four were selected given they are commonly reported outcomes for amputees and are interrelated with service delivery (23-25).

\section{Statistical analyses}

Descriptive analyses were conducted to assess trends in amputation rates and outcomes following hospitalisation with comparison drawn between the three largest public hospitals in South Australia. Clinical outcomes of time to death (following initial amputation) and up-transfers (patient transfer to another hospital for specialist inpatient treatment not available at the primary hospital) were analysed to describe the three hospital services presented. Comparisons across hospitals were made using one-way analysis of variance (ANOVA) for continuous outcomes, and pearson chi-square for categorical outcomes. Level of statistical significance was set at $\mathrm{p} \leq 0.05$.

To assess hospital performance, a risk adjusted analysis of LOS and patient outcomes based on the four endpoints was undertaken, for which the difference between observed (actual) and expected values for each intermediate endpoint were estimated. Differences between observed and expected values for each intermediate endpoint were considered a measure of hospital performance. Expected outcome values for LOS and patient outcomes were estimated using separate generalised linear statistical models, as applied in previous risk adjusted cost-effectiveness analyses $(19,26$, 27). Briefly, generalised linear models were constructed with backwards stepwise selection using the full range of demographic, socioeconomic, and clinical explanatory variables (comorbidities, admission type, primary and additional diagnoses and procedures) which were extracted from three separate datasets (ISAAC, Register of Births, Deaths and Marriages and area codes). The criterion for inclusion in the model was $\mathrm{p} \leq 0.05$. These initially defined models were expanded to test for significant interactions between the included explanatory variables. Interaction terms were included if they improved model fit as judged by the Akaike information criterion which is a measure of the relative quality of the statistical model. The modified Park test was used to ensure the most appropriate distribution. The appropriate link function was selected by testing different power functions with respect to the Pearson correlation, Pregibon link, and the Modified Hosmer-Lemeshow tests. These techniques ensured the constructed models 
Table 1

Demographics and clinical characteristics of the 3 key hospitals is South Australia from July 2001 to June 2008

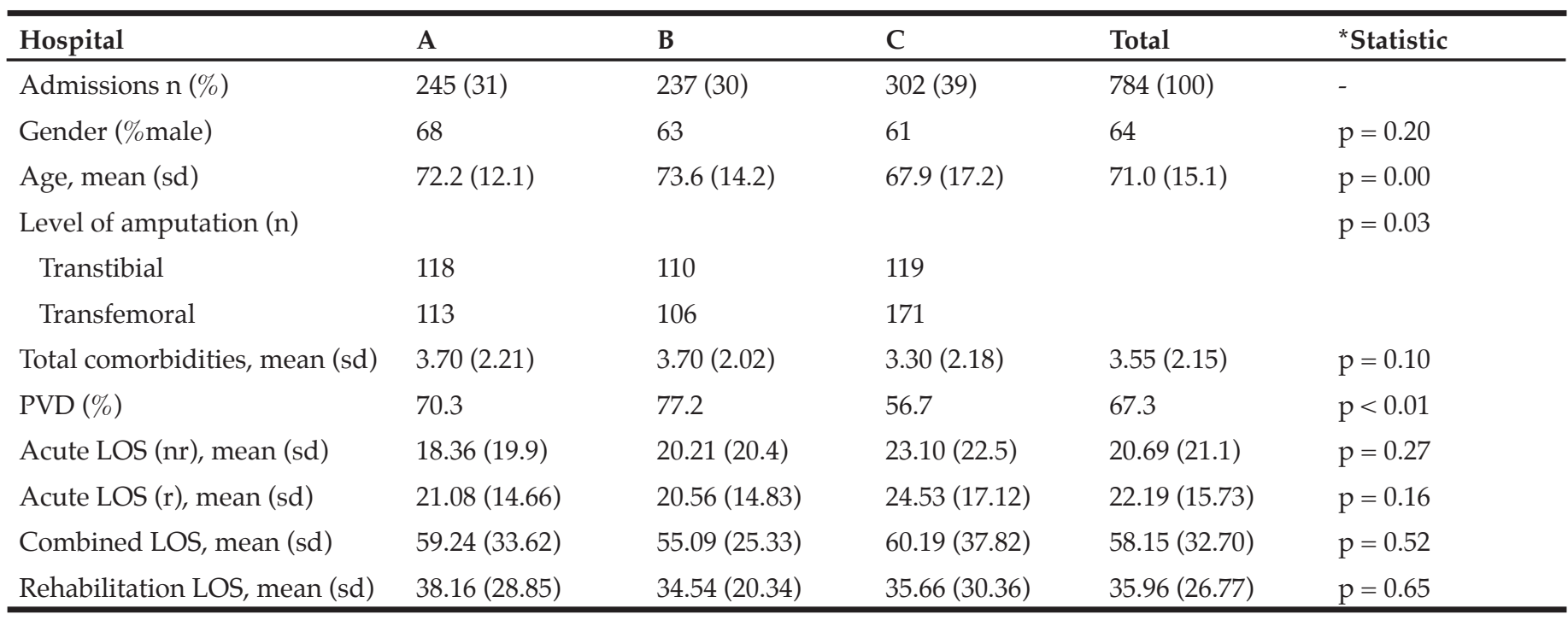

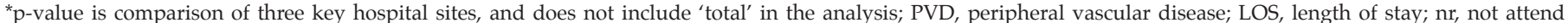
rehabilitation; r, attended rehabilitation; combined LOS, rehabilitation and acute length of stay combined.

adequately described expected outcomes for LOS and patient outcomes for the four intermediate endpoints.

Following determination of appropriate statistical models, risk adjusted LOS and patient outcome estimates for each patient were generated as the relevant observed minus expected values, which can be interpreted as risk adjusted differences in LOS and patient outcome. This method provides a more intuitive interpretation of hospital performance than 'observed divided by expected' adjusted values as previously reported (26). For the risk adjusted performance evaluation of LOS separate ANOVAs were performed to compare standardised LOS (observed LOS minus expected LOS) between the three key hospitals for each year of analysis. Where statistically significant differences were observed, Bonferroni posthoc analyses were performed. Statistical significance was set at $\mathrm{p} \leq 0.05$. All analyses were undertaken using Stata Software (StataCorp, 2009, Stata Statistical Software: Release 11, College Station, TX, USA).

\section{Results}

A total of 1076 lower-limb amputation episodes were identified as occurring in all South Australian public hospitals between June 2001 and July 2008. Of these, 784 $(73 \%)$ separations were associated with three major South Australian hospitals (identified as hospital A, hospital B, and hospital C).

\section{Nature of hospital service}

A summary of demographics and clinical characteristics between the three key hospital services is provided in table 1 . Hospital $\mathrm{C}$ was the largest hospital of the three key hospitals for amputee services in South Australia (39\% of episodes) however there was little variation in the volume of services delivered at the three amputee hospital sites. The age of amputees differed significantly between the sites with hospital $\mathrm{C}$ having significantly lower aged amputee episodes than both hospital A and $B(F(2,515)=9.50, p<0.001)$. There were differences in levels of amputation between the three key hospital (X2 (2) =7.02, p = 0.03). Hospital $\mathrm{C}$ had a greater proportion of transfemoral amputees compared to hospital A and hospital B. Mean number of comorbidities was considered high across all three sites, with the average being 3.55 (SD 2.15) comorbidities. Multiple (two or more) comorbidities were high across all three sites with $85 \%$ of episodes at hospital A and $84 \%$ at hospital B having multiple comorbidities. Fewer episodes with multiple comorbidities were observed at hospital C $(78 \%)$ than at hospitals A and B, but this was not statistically significantly $(\mathrm{X} 2(2)=3.43, \mathrm{p}=0.180)$. Hospitals A and B had significantly higher incidences of PVD as a comorbidity compared to hospital C (X2 (2) $=19.11, \mathrm{p}<0.001)$. Combining this with the variations in age at these hospital services, hospitals A and B were at higher risk of admitting elderly vascular episodes, compared to hospital $\mathrm{C}$ which appeared more likely to admit younger (possibly traumatic) episodes. Despite this, analysis of both acute and rehabilitation unadjusted LOS revealed no significant differences between hospital sites.

Given the high incidence of multiple comorbidities observed for episodes across all three sites, up-transfers and time to death across all three sites were investigated. Between July 2002 and June 2008, there were 15 up-transfers. Nine $(60 \%)$ of these transfers occurred at hospital A, none at hospital B and six $(40 \%)$ at hospital 
Table 2

Standardised outcomes for three main amputee public hospitals in South Australia

\begin{tabular}{lcccc}
\hline Hospital & $\begin{array}{c}\text { No event within } \\
\mathbf{1 2} \text { months }\end{array}$ & $\begin{array}{c}\text { Amputation of another } \\
\text { limb within 12 months }\end{array}$ & $\begin{array}{c}\text { Stump revision within } \\
\mathbf{1 2} \text { months }\end{array}$ & $\begin{array}{c}\text { Death within } \\
\mathbf{1 2} \text { months }\end{array}$ \\
\hline A & $-3.13 \%$ & $3.04 \%$ & $1.31 \%$ & $-1.22 \%$ \\
B & $1.61 \%$ & $-0.06 \%$ & $1.34 \%$ & $-2.89 \%$ \\
C & $-1.31 \%$ & $0.05 \%$ & $-1.09 \%$ & $2.36 \%$ \\
\hline * standardised - observed minus expected probability (i.e. a negative $\%$ indicates the hospital has a smaller event rate than expected, controlling for casemix)
\end{tabular}

${ }^{*}$ standardised - observed minus expected probability (i.e. a negative \% indicates the hospital has a smaller event rate than expected, controlling for casemix)

Table 3

Standardised LOS across the three main amputee public hospitals in South Australia

\begin{tabular}{|c|c|c|c|c|c|c|}
\hline Year & & Hospital A & Hospital B & Hospital C & All Hospitals & Statistic \\
\hline \multirow[t]{4}{*}{$2002 / 03$} & Separations (N) & 36 & 20 & 50 & 106 & \\
\hline & Observed (LOS) & 48.44 & 61.95 & 37.45 & 45.81 & \\
\hline & Expected (LOS) & 39.31 & 40.34 & 38.71 & 39.22 & \\
\hline & Standardised (LOS) & 9.14 & 21.61 & -1.25 & 6.59 & $p=0.04$ \\
\hline \multirow[t]{4}{*}{$2003 / 04$} & Separations (N) & 21 & 29 & 36 & 86 & \\
\hline & Observed (LOS) & 32.05 & 42.66 & 38.14 & 38.17 & \\
\hline & Expected (LOS) & 39.69 & 36.57 & 36.31 & 37.22 & \\
\hline & Standardised (LOS) & -7.64 & 6.09 & 1.82 & 0.95 & $\mathrm{p}=0.12$ \\
\hline \multirow[t]{4}{*}{$2004 / 05$} & Separations (N) & 26 & 24 & 26 & 76 & \\
\hline & Observed (LOS) & 32.35 & 45.43 & 39.92 & 38.97 & \\
\hline & Expected (LOS) & 40.38 & 37.87 & 40.31 & 39.56 & \\
\hline & Standardised (LOS) & -8.04 & 7.25 & -0.38 & -0.59 & $p=0.06$ \\
\hline \multirow[t]{4}{*}{$2005 / 06$} & Separations (N) & 31 & 31 & 31 & 93 & \\
\hline & Observed (LOS) & 39.39 & 31.81 & 34.94 & 35.38 & \\
\hline & Expected (LOS) & 40.38 & 39.00 & 41.06 & 40.15 & \\
\hline & Standardised (LOS) & -0.99 & -7.2 & -6.12 & -4.77 & $\mathrm{p}=0.33$ \\
\hline \multirow[t]{4}{*}{$2006 / 07$} & Separations (N) & 31 & 32 & 30 & 93 & \\
\hline & Observed (LOS) & 32.90 & 33.91 & 58.47 & 41.49 & \\
\hline & Expected (LOS) & 37.93 & 39.68 & 41.90 & 39.82 & \\
\hline & Standardised (LOS) & -5.03 & -5.78 & 16.56 & 1.68 & $\mathrm{p}=0.07$ \\
\hline \multirow[t]{4}{*}{$2007 / 08$} & Separations (N) & 27 & 35 & 37 & 99 & \\
\hline & Observed (LOS) & 28.37 & 32.57 & 40.89 & 34.54 & \\
\hline & Expected (LOS) & 39.83 & 37.72 & 39.73 & 39.04 & \\
\hline & Standardised (LOS) & -11.46 & -5.15 & 1.17 & -4.51 & $\mathrm{p}=0.17$ \\
\hline \multirow[t]{4}{*}{ All years } & Separations (N) & 172 & 171 & 210 & 553 & \\
\hline & Observed (LOS) & 36.42 & 39.59 & 41.11 & 39.18 & \\
\hline & Expected (LOS) & 39.54 & 38.45 & 39.48 & 39.18 & \\
\hline & Standardised (LOS) & -3.12 & 1.14 & 1.63 & 0.00 & $\mathrm{p}=0.10$ \\
\hline
\end{tabular}

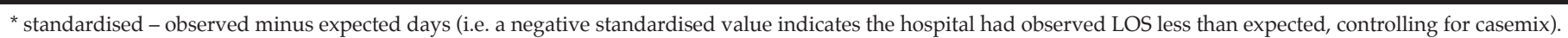
LOS, length of stay. 
C. Median time to death for all lower-limb amputees in South Australia was 295 days (IQR 75-773 days). Analysis of time to death (unadjusted) for the three key South Australian hospitals revealed no significant differences $(\mathrm{F}(2,300)=1.44, \mathrm{p}=0.239)$, with median time to death at hospital A of 344 days (IQR 92-998 days), hospital B 352 days (range 136-765 days), and hospital C 205 days (range 55-609 days). At 12 months, no significant differences were observed in the number of episodes identified as 'dead' between the three key hospitals $(X 2(2)=0.280, p=$ 0.88 ) with hospital A reporting death in $25 \%$ of episodes, hospital B 23\%, and hospital C 26\%.

\section{Risk adjusted performance analysis}

A risk adjusted performance analysis was performed on episodes where the initial lower-limb amputation was able to be identified $(n=553)$. Mean risk adjusted patient outcome events and LOS were analysed over the 12 months subsequent to the index amputation and evaluated at each of the three hospitals. The majority of patients $(62 \%)$ experienced no subsequent event, $7 \%$ experienced a subsequent lower-limb amputation, $6 \%$ a stump revision, and $25 \%$ died within 12 months across the three sites. After adjusting for baseline risk of subsequent events, hospital B appeared to achieve the best outcomes, with less than expected subsequent lower-limb amputations, and less than expected deaths. Hospital A appeared next best with less than expected deaths following the initial amputation; however there were more than expected stump revisions and subsequent lower-limb amputations following the initial amputation. Hospital $\mathrm{C}$ had the poorest outcome data with patients experiencing more than expected subsequent lower-limb amputations and deaths. Outcome events for the four defined endpoints are provided in table 2. Outcomes from the risk adjusted performance evaluation for LOS are provided in table 3. Standardised LOS (calculated as observed LOS minus expected LOS) was significantly different between the three key hospitals in 2002-03 $(\mathrm{F}(2)=2.71, \mathrm{p}=0.04)$ and 2006-07 $(\mathrm{F}(2)=4.47, \mathrm{p}=0.01)$. Post-hoc analysis found that in 2002-03 hospital $C$ had significantly lower standardised LOS compared to hospital B $(\mathrm{t}(68)=$ 5.54, $\mathrm{p}=0.02$ ). In 2006-07, post-hoc analysis found that hospital $C$ had significantly greater standardised LOS compared to both hospital A $(\mathrm{t}(59)=5.09, \mathrm{p}=0.03)$, and hospital $\mathrm{B}(\mathrm{t}(60)=7.30, \mathrm{p}=0.01)$. Although not reaching statistical significance, there were trends for greater hospital performance (lower standardised LOS) at hospital A overall $(\mathrm{p}=0.10)$. For 2002-08, both hospital B and hospital $\mathrm{C}$ had observed LOS greater than expected across all years.

\section{Discussion}

In this study we utilised readily available individual patient-level data to assess performance and efficiency of lower-limb amputee services at three neighbouring public hospitals in one Australian city. We assessed lower-limb amputee services (across acute and rehabilitation settings) by comparing standardised LOS and performance over four intermediate outcomes, commonly associated with lower-limb amputation, in the 12 months following the initial amputation. The key findings of this study were that hospital A achieved best performance based on standardised LOS, while hospital $\mathrm{B}$ was associated with better performance based on intermediate outcomes following the initial amputation. The methodology presented here represents an effective technique to evaluate hospital performance and may be used for a range of clinical presentations to improve hospital service provision.

This study demonstrated that hospital A and B had better performance for amputee service provision based on standardised LOS and performance outcomes respectively. These findings may be explained by variation in service provision of the three hospitals reported here. Two hospitals (hospitals A and C) were structured with geographically separate acute vascular and prosthetic rehabilitation services. Hospital B however co-located the acute vascular and prosthetic rehabilitation services. Results from this study indicate that hospital B was associated with better outcomes (fewer than expected deaths and subsequent amputations) compared to hospital A and hospital C. The better outcomes observed at hospital B are possibly a result of improved continuity of care and communication between acute and rehabilitation teams with readier access to surgeons for advice around complications. However, better outcomes at hospital B did not translate into lower than expected LOS overall. Increased hospital costs are typically associated with long total LOS, and the overall LOS associated with this condition were very high across all three hospitals compared to other clinical populations $(12,13)$. The lack of step down facilities and the per diem payment system in South Australia may have contributed to the long LOS across all hospitals. Despite this, hospital B was more efficient than hospital $\mathrm{C}$ with regards to LOS, and combined with better outcomes observed at hospital B, there is some evidence that co-locating acute and rehabilitation services results in improved service delivery. We therefore consider hospital B to be the better performing hospital in this analysis (best patient outcomes), with hospital A having the best (lower than expected) LOS. Hospital C appears to be dominated by hospital A and hospital B with longer than expected LOS and poor patient outcomes. This may be a reflection of different amputee episodes admitted to this hospital. Amputees were younger and more likely to be transfemoral, potentially reflecting trauma as opposed 
to elective vascular surgery. Medical complexities associated with the trauma may have contributed to reduced performance at this hospital, however further analysis is required to investigate this.

We acknowledge that other variations in hospital service provision may have contributed to the findings presented here. For example, hospital specialities, hospital locations, duration and frequency of rehabilitation sessions and availability of prosthetic services may potentially confound these results. However, this risk adjusted performance analysis framework may be best viewed as providing the necessary evidence to inform further investigations around variation in hospital efficiency. In this instance, we suggest more detailed investigation is required to understand what the relevant differences in clinical care between co-located and off-site rehabilitation facilities.

Our measure of efficiency was derived from the difference between observed and expected outcomes that were standardised to account for differences between the characteristics of patients presenting at each hospital. We concede that efficiency can be measured in various ways and that various measures can be explored by a variety of econometric techniques. In this study we chose to use the risk adjusted performance analysis framework because of its potential to utilise patient level data to explore efficiency at the condition (ie lower-limb amputation) level (19). We note that there are other commonly available techniques and that as with all empirical studies the results of our study are a function of the estimation approaches. However, we feel that the risk adjusted performance analysis approach is particularly appropriate in assessing linked routinely collected data such as ours. Other techniques including data envelopment analysis may be used to evaluate the relative efficiency of hospitals based on combination of multiple inputs and outputs. We consider the results from our analysis to be valid given that the risk adjusted performance evaluation methodology employs standard statistical (eg generalised linear modelling) and health economics (eg decision analytic) approaches (28). Further, model specification and goodness of fit assessments conformed to established norms (29).

Interestingly, findings from this study indicate a high mortality rate $(25 \%)$ in the 12 months following limb amputation and overall a short time to death (median 0.8 years following amputation, IQR 0.21-2.12 years). The lack of variation between hospitals in these outcomes suggests that many amputees are complex and their health care costs and long LOS are largely driven by the high rate of complications associated with the medical conditions that resulted in amputation, rather than by clinical or organisational processes associated with the amputation. Nevertheless, we were able to distinguish differences across hospitals in rates of deaths, stump revision and subsequent amputations suggesting that they would be areas where clinical practice could be examined and possible efficiency gains could be made.

A key limitation of this study is the lack of outcomes to describe function, quality of life or other patient reported outcomes which are important when comparing hospital service models across a population. Although the identified intermediate categories (no event, another amputation, stump revision, and death) are used to determine outcomes of service, we acknowledge the lack of mobility related outcomes, which are of significance to the quality of life of an amputee population. We also acknowledge the use of routinely collected data and the biases that may follow; for instance, from the sample period and completeness of data capture. A potential weakness of our study is that lower-limb amputee services (eg ambulatory services) that are not organised at the inpatient hospital level have been excluded from our analysis.

In conclusion, amputee care requires extensive hospital stays which are potentially costly, raising questions about investment in vascular and rehabilitation services at end of life. It is important to note that without amputation many of these people would have died in pain but providing the most efficient service in this study was associated with less re-amputations and fewer deaths. Avoiding multiple amputations and surgeries is likely to improve quality of life. Ensuring services are efficient is likely to reduce not only hospital LOS and associated costs, but suffering at the end of life. This study utilised patient level, routinely collected and linked data, in identifying efficient clinical practice. The results identified the integrated service with co-located acute and rehabilitation facilities as providing better patient level outcomes in terms of revisions and re-amputations. Further studies are needed to explore these provisional findings, especially in terms of understanding the role of variation in the nature of services, so that efficient and effective practices can be identified and disseminated. Using readily available administrative data, this methodology, a risk adjusted performance analysis, could allow monitoring of the efficiency of vascular and rehabilitation service provision for amputees at alternative hospital networks.

\footnotetext{
Acknowledgements: There are no acknowledgements

Funding: Brenton Hordacre was the recipient of an Australian Postgraduate Award.

Conflict of interest: The authors declare no conflicts of interest
}

Ethical Standards: This study was approved by South Australian Department of the Health Human Research Ethics Committee.

\section{References}

1. Eckel RH, Grundy SM, Zimmet PZ. The metabolic syndrome. Lancet 2005;365:1415-28.

2. Hu FB. Globalization of diabetes: The role of diet, lifestyle, and genes Diabetes Care 2011;34:1249-57.

3. Moxey P, Hofman D, Hinchliffe R, Jones K, Thompson M, Holt P Epidemiological study of lower limb amputation in england between 2003 
and 2008. Br J Surg 2010;97:1348-53.

4. Hordacre BG, Stevermuer T, Simmonds F, Crotty M, Eagar K. Lower-limb amputee rehabilitation in australia: Analysis of a national data set 2004-10. Aust Health Rev 2013;37:41-47.

5. Hordacre B, Birks V, Quinn S, Barr C, Patritti BL, Crotty M. Physiotherapy rehabilitation for individuals with lower limb amputation: A 15-year clinical series. Physiother Res Int 2013;18:70-80.

6. Nehler MR, Coll JR, Hiatt WR, et al. Functional outcome in a contemporary series of major lower extremity amputations. J Vasc Surg 2003;38:7-14.

7. Stone PA, Flaherty SK, Hayes JD, AbuRahma AF. Lower extremity amputation: A contemporary series. W V Med J 2007;103:14-18.

8. Varu VN, Hogg ME, Kibbe MR. Critical limb ischemia. J Vasc Surg 2010;51:230-41.

9. Becker F, Robert-Ebadi H, Ricco JB, et al. Chapter i: Definitions, epidemiology, clinical presentation and prognosis. Eur J Vasc Endovasc Surg 2011;42, Supplement 2:S4-S12.

10. Carmona GA, Hoffmeyer P, Herrmann FR, et al. Major lower limb amputations in the elderly observed over ten years: The role of diabetes and peripheral arterial disease. Diabetes Metab 2005;31:449-54.

11. Beckman JA, Creager MA, Libby P. Diabetes and atherosclerosis epidemiology, pathophysiology, and management. J Am Med Assoc 2002;287:2570-81.

12. Simmonds F, Stevermuer T. The aroc annual report: The state of rehabilitation in australia 2005. Aust Health Rev 2007;31 Suppl 1:31-53.

13. Simmonds F, Stevermuer T. The aroc annual report: The state of rehabilitation in australia 2006. Aust Health Rev 2008;32:85-110.

14. Abou-Zamzam Jr AM, Gomez NR, Molkara A, et al. A prospective analysis of critical limb ischemia: Factors leading to major primary amputation versus revascularization. Ann Vasc Surg 2007;21:458-63.

15. Abola MTB, Bhatt DL, Duval S, et al. Fate of individuals with ischemic amputations in the reach registry: Three-year cardiovascular and limbrelated outcomes. Atherosclerosis 2012;221:527-35.

16. Henry AJ, Hevelone ND, Belkin M, Nguyen LL. Socioeconomic and hospitalrelated predictors of amputation for critical limb ischemia. J Vasc Surg 2011;53:330-39.

17. Moxey PW, Gogalniceanu P, Hinchliffe RJ, et al. Lower extremity amputations - a review of global variability in incidence. Diabet Med
2011;28:1144-53.

18. Duckett S, Coory M, Kamp M, Collins J, Skethcher-Baker K, Walker K. Vlads for dummies. Milton, Qld: Wiley Publishing Australia Pty Ltd, 2008.

19. Karnon I, Caffrey O, Pham $\mathrm{C}$, et al. Applying risk adjusted cost-effectiveness (rac-e) analysis to hospitals: Estimating the costs and consequences of variation in clinical practice. Health Econ 2013;22:631-42.

20. Young BA, Maynard C, Reiber G, Boyko EJ. Effects of ethnicity and nephropathy on lower-extremity amputation risk among diabetic veterans. Diabetes Care 2003;26:495.

21. Payne CB. Diabetes-related lower-limb amputations in australia. Med J Aust 2000;173:352-54.

22. Ziegler-Graham K, MacKenzie EJ, Ephraim PL, Travison TG, Brookmeyer R. Estimating the prevalence of limb loss in the united states: 2005 to 2050. Arch Phys Med Rehabil 2008;89:422-29.

23. Johannesson A, Larsson G-U, Ramstrand N, Turkiewicz A, Wiréhn A-B, Atroshi I. Incidence of lower-limb amputation in the diabetic and nondiabetic general population a 10-year population-based cohort study of initial unilateral and contralateral amputations and reamputations. Diabetes Care 2009;32:275-80.

24. Dillingham TR, Pezzin LE, Shore AD. Reamputation, mortality, and health care costs among persons with dysvascular lower-limb amputations. Arch Phys Med Rehabil 2005;86:480-86.

25. Dillingham TR, Pezzin LE. Rehabilitation setting and associated mortality and medical stability among persons with amputations. Arch Phys Med Rehabil 2008;89:1038-45.

26. Pham C, Caffrey O, Ben-Tovim D, Hakendorf P, Crotty M, Karnon J. Evaluating the effects of variation in clinical practice: A risk adjusted costeffectiveness (rac-e) analysis of acute stroke services. BMC Health Serv Res 2012;12

27. Karnon J, Afzali HHA, Gray J, Holton C, Banham D, Beilby J. A risk adjusted cost-effectiveness analysis of alternative models of nurse involvement in obesity management in primary care. Obesity 2013;21:472-79.

28. Briggs A, Claxton K, Sculpher M. Decision modelling for health economic evaluation: Oxford, 2006.

29. Greene W. Econometric analysis (5th edition). 5th ed. Upper Saddle River, NJ: Prentice Hall, 2003. 